\title{
Correlation between Small-Scale Rate of Heat Release and Full-Scale Room Flashover for Surface Linings
}

\author{
B. A.-L. ÖSTMAN and R. M. NUSSBAUM \\ Swedish Institute for Wood Technology Research \\ Box 5609, S-114 86 Stockholm, Sweden
}

\section{ABSTRACT}

A very simple empirical relationship has been found for predicting the time to flashover in a full-scale room fire test for surface lining materials. It is based on bench-scale measurements of rate of heat release in the cone calorimeter. The relation also includes the time to ignition and the density of the linings.

$T=a \times \frac{t \cdot \sqrt{\rho}}{A}+b$

where $T$ is time to flashover in full scale, $t$ is time to ignition in small scale at $25 \mathrm{~kW} / \mathrm{m}^{2}, A$ is heat release during peak period at $50 \mathrm{~kW} / \mathrm{m}^{2}, \rho$ is density, $a$ and $b$ are constants.

It is valid for the eleven different surface linings which caused flashover. They included both fully combustible and essentially nonmcombustible materials, with or without thin surface coverings. Two linings did not cause flashover and can not be directly correlated, but their small-scale data indicate longer times to flashover than for the other lining materials. However, the application of the relationship for other surface materials or other full-scale fire scenarios has not yet been investigated.

\section{INTRODUCTION}

The early fire behaviour of materials is important for many aspects of fire safety. New fire tests are in development $e . q$. within ISO $(8,17)$ in order to determine and characterize the fire behaviour in a more elaborate way than the present national test methods. One main aspect in the development is that no classes of materials should be precluded from testing $\mathrm{e} \cdot \mathrm{g}$. melting materials. Other aspects are that the new tests should be physically well-defined and also have a clear connection to some "real" fire behaviour. 
The new tests are both in small and full scales. Small-scale tests are necessary as practical tools and are satisfactory for most purposes. Full-scale tests are needed to validiate the small-scale tests and are generally considered to be more reliable, although not necessarily more reproducible.

Small-scale tests often evaluate distinct fire parameters such as time to ignition, spread of flame, heat and smoke release. Among these, the rate of heat release, RHR, has proven to be of most interest in recent years. A preferable version is the so called cone calorimeter (1, $3)$, but the RHR parameters seem not to be dependant on test equipment ( 5 , 19).

Full-scale tests for building materials are often of a room/corner configuration, of which there are similar versions according to ASTM and $\operatorname{ISO}(2,7,11)$.

The relations between these small-scale and full-scale tests are not yet fully understood. Mathematical models $(10,13,14,18)$ and physical relations (4) have been proposed recently providing good agreement for at least some materials. This paper describes another approach: a simple empirical correlation between parameters determined in small and full scale. However, the parameters are chosen because they have basic significance and are assumed to have a physical meaning for the early fire be-haviour of surface linings. The proposed correlation may also be further developed to predict a full-scale fire when more materials have been tested. Here it is applied to the 13 materials tested, which included both combustible and non combustible materials.

Such relationships are necessary to make full use of the new fire test methods as predictive tools for building design purposes.

\section{EXPERIMENTAL}

Small-scale rate of heat release was determined in a cone calorimeter with horizontal specimens (12). The data for sample size $100 \times 100 \mathrm{~mm}$ was used in order to be in full accordance with the ASTM-version (1, 3 ). Constant heat flux levels of 25,50 and $75 \mathrm{~kW} / \mathrm{m}^{2}$ were performed. Besides heat release data, the time to ignition was recorded and used in the calculations.

Full-scale behaviour was determined according to the full-scale room fire test for surface products specified by ISO (7) and standardized by Nordtest (11). It is similar to the ASTM version. The dimensions of the room are $3.6 \mathrm{~m} \times 2.4 \mathrm{~m} \times 2.4 \mathrm{~m}(1 \times \mathrm{w} \times \mathrm{h})$. A doorway $(0.8 \mathrm{~m} \times 2.0 \mathrm{~m}) \mathrm{in}$ one of the side-walls allows for ventilation. Walls and ceiling are covered with the surface lining material being tested. An ignition source of $100 \mathrm{~kW}$ is placed in one of the inner corners. If flashover does not occur within 10 minutes, the ignition source is raised to $300 \mathrm{~kW}$. A large number of variables are measured in this tests, but in this paper only the time to flashover will be used for characterizing the fire behaviour of the tested materials. The full-scale tests were performed at the Swedish National Testing Institute (15). 
The thermal inertia was determined in separate ignitability tests (10) according to ISO (9). Data for expanded polystyrene were not included but obtained from technical specifications by the manufacturer.

The test materials are listed in Table 1 , which also specifies the densities used in the calculations. All the test samples originate from the same lot which was initially selected and used for several studies on reaction to fire within Scandinavian fire laboratories. All samples were conditioned to equilibrium in $50 \%$ relative humidity at $23^{\circ} \mathrm{C}$ before being tested.

TABLE I. Test materials and time to flashover.

\begin{tabular}{lccc}
\hline Material & $\begin{array}{c}\text { Thickness } \\
\mathrm{mm}\end{array}$ & $\begin{array}{c}\text { Density } \\
\mathrm{kg} / \mathrm{m}^{3}\end{array}$ & $\begin{array}{c}\text { Full scale } \\
\text { time to } \\
\text { flashover } \\
\text { min:s }\end{array}$ \\
\hline Rigid polyurethane foam & 30 & 32 & $0: 14$ \\
Textile wall-covering on rock-wool & $42+0.5$ & 150 & $0: 55$ \\
Insulating fiber board & 13 & 250 & $1: 07$ \\
Expanded polystyrene & 49 & 18 & $2: 12$ \\
Medium density fiber board & 12 & 655 & $2: 14$ \\
Wood panel (spruce) & 11 & 450 & $2: 18$ \\
Paper wall-covering on particle board & $10+0.5$ & 670 & $2: 22$ \\
Particle board & 10 & 670 & $2: 30$ \\
Melamine-faced particle board & 13 & 870 & $7: 45$ \\
Plastic wall-covering on gypsum board & $13+0.7$ & 725 & $10: 151$ \\
Textile wall-covering on gypsum board & $13+0.5$ & 725 & $10: 371$ \\
Paper wall-covering on gypsum board & $13+0.5$ & 725 & No \\
Gypsum board & 13 & 725 & No \\
\hline
\end{tabular}

1) Flashover was reached only after increase of burner heat output at 10:00 min.

CORRELATION BETWEEN SMALL AND FULL SCALE

The aim has been to find a relation between basic parameters from a small-scale RHR test and a full-scale room test. For the small-scale, RHR parameters are expressed in well defined physical units and can be determined accurately at different heat fluxes. For the full-scale, the time to flashover from a standard test was chosen as being the most obvious and simple parameter. The procedure to find a relation can best be expressed as "trial and error". 
The most straightforward relation would be to correlate a heat release parameter directly to flashover. Available parameters may include peak RHR, average RHR for a defined time period including or not including time to ignition, and also the total heat release, THR, during some time period, see Figure 1. The peak RHR has been used in some cases (5) but none of the parameters mentioned above was successful for the data analysed here. An exanple is given in Figure 2, in which THR during peak period is used. (After the minimum in RHR, a second peak is obtained, including sample edge effects which are not relevant for a surface application, see also Figure 3.) No correlation was obtained. The reason seems to be that high peaks of RHR and a non-negligjble THR are obtained also for some materials with long times to flashover, which make it difficult to separate them from materials with short time to flashover.

A direct correlation between time to ignition in small scale and full-scale time to flashover is neither successful for similar reasons, also in Figure 2.
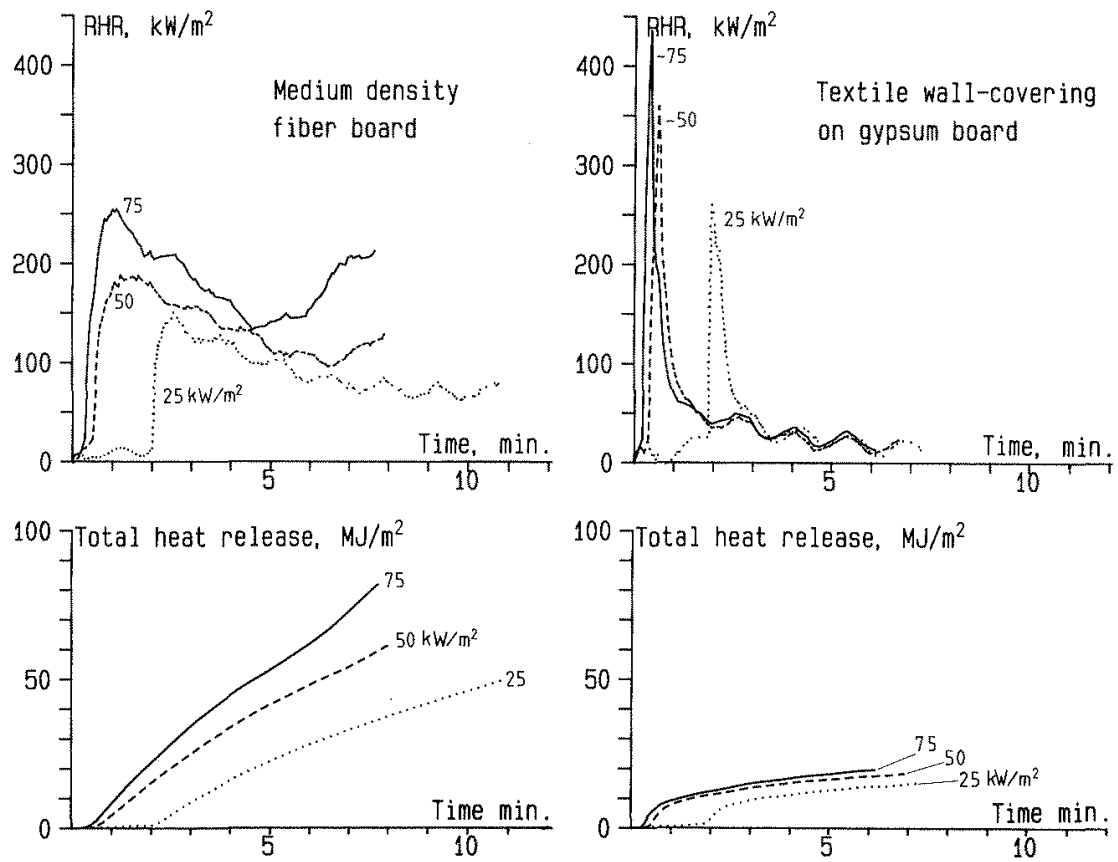

FIGURE 1. Examples of rate of heat release (RHR) and total heat release as determined in the cone calorimeter at different incident heat fluxes. 
(1) Particle board

* Insulating fiber board

a Medium density fiber board

* Wood panel (spruce)

- Paper wall-covering on particle boaro $\times$ Melamine-faced particle board

+ Textjle wall-covering on rock-wool

$\Delta$ Rigid polyurethane foam

- Expanded polystyrene
- Gypsum board

- Paper wall-covering on g.b.

- Plastic wall-covering on g.b.

- Textile wall-covering on $g . b$

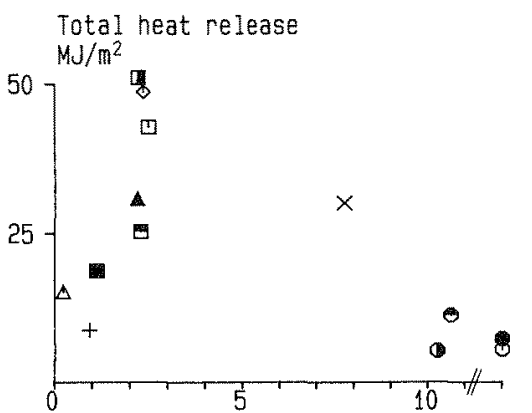

Full scale: Time to flashover, min.

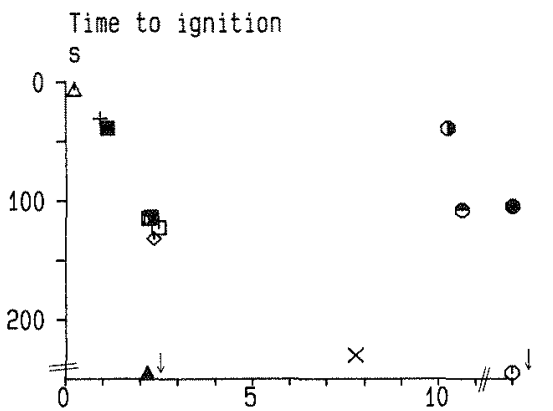

Full scale: Time to flashover, min.

FIGURE 2. To the Ieft: Total heat release during peak period at $50 \mathrm{~kW} / \mathrm{m}^{2}$ heat flux in the cone calorimeter. To the right: Time to ignition (determined in the cone calorimeter $\mathrm{at} \overline{2} 5 \mathrm{~kW} / \mathrm{m}^{2}$ ). Both parameters are plotted versus time to flashover in full scale and give examples of no correlation.

$\mathrm{BHR}, \mathrm{kW} / \mathrm{m}^{2}$

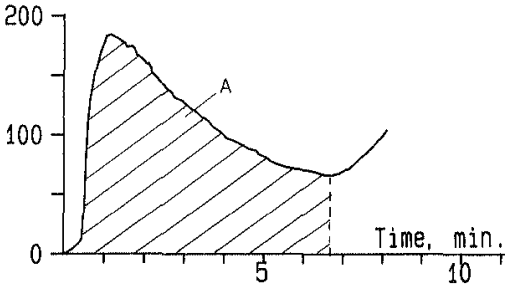

$\mathrm{RHA}, \mathrm{kW} / \mathrm{m}^{2}$

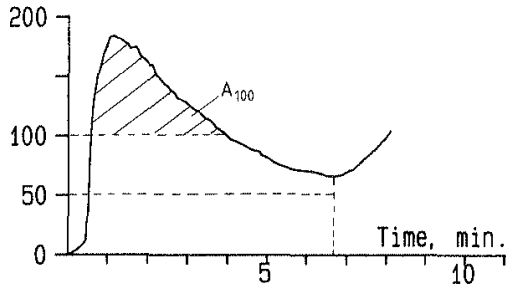

FIGURE 3. Principle sketch of total heat release during peak period after which edge effects are obtained. The right diagram includes a baseline correction tried for a better fit to full-scale behaviour.

However, a combination of heat release and time to ignition provides a somewhat better correlation. Out of different combinations it seems preferable to combine the total heat release at any heat flux with the time to ignition at $25 \mathrm{~kW} / \mathrm{m}^{2}$, the latter chosen because the accuracy in time to ignition is better at low heat fluxes. 
Still better correlation is obtained if the density of the material is considered as well, see Table 2. Some improvement is also obtained by extracting the square root of the density, while the full thermal inertia $\sqrt{\mathrm{kpc}}(16)$ will not give any further improvement. Adding a new dependent parameter will, thus, not improve the correlation, which also have been shown in an earlier study (6). In this case, the density and the thermal conductivity of the material are roughly proportional.

Another thought was to consider the RHR above a certain basic level e.g. 50 or $100 \mathrm{~kW} / \mathrm{m}^{2}$, see Figure 3. It is justified because a certain RHR seems to be negligible in predicting flashover. However, the results do not provide any further advantage, see Table 3.

TABLE 2. Correlation coefficients between different smallscale parameters and time to flashover in full scale.

\begin{tabular}{lccc}
\hline $\begin{array}{l}\text { Smal1-scale } \\
\text { parameter * }\end{array}$ & $251)$ & 50 & $751), 2)$ \\
\hline$t / A$ & 0.678 & 0.627 & 0.927 \\
$t \cdot \rho / A$ & 0.937 & 0.949 & 0.958 \\
$t \cdot \sqrt{\rho} / A$ & 0.939 & 0.963 & 0.949 \\
$t \cdot \sqrt{k \cdot \rho \cdot c / A}$ & 0.934 & 0.935 & 0.926 \\
\hline
\end{tabular}

\begin{tabular}{|c|c|c|}
\hline * & $\begin{array}{l}A \\
t \\
P \\
\sqrt{k \cdot \rho \cdot c}\end{array}$ & $\begin{array}{l}=\text { heat release during peak period } \\
=\text { time to ignition at } 25 \mathrm{~kW} / \mathrm{m}^{2} \text { heat flux } \\
=\text { density of lining material } \\
=\text { thermal inertia. }\end{array}$ \\
\hline 1) & $\begin{array}{l}\text { No date } \\
\text { Polyure }\end{array}$ & $\begin{array}{l}\text { for melamine-faced particle board. } \\
\text { ethane and polystyrene not tested. }\end{array}$ \\
\hline
\end{tabular}

TABLE 3. Correlation coefficients for small-scale RHR-data including a baseline correction as in Figure 3 .

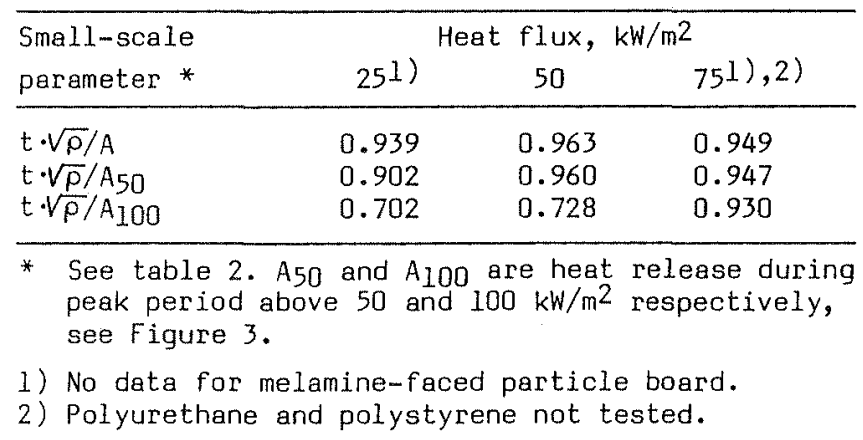


Among the different data in Table 2, one correlation seems to be better than the others. This is the correlation for heat release at $50 \mathrm{~kW} / \mathrm{m}^{2}$ incident heat flux without any baseline correction combined with the time to ignition at $25 \mathrm{~kW} / \mathrm{m}^{2}$ and the square root of the density. The RHR and ignition data used for the calculations are given in Table 4 and the density in Table 1. The corresponding curve is given in Figure 4 and provides a reasonable fit.

The relation may be described by the equation

$$
T=a \times \frac{t \cdot \sqrt{\rho}}{A}+b
$$

where $T=$ time to flashover in full scale, $s$

$t=$ time to ignition in small scale at $25 \mathrm{~kW} / \mathrm{m}^{2}, \mathrm{~s}$

$A=$ heat release during peak period at $50 \mathrm{~kW} / \mathrm{m}^{2}, \mathrm{~J} / \mathrm{m}^{2}$

$\rho=$ density, $\mathrm{kg} / \mathrm{m}^{3}$

$a=$ constant, $2.76 \cdot 10^{6} \mathrm{~J} \cdot(\mathrm{kg} \cdot \mathrm{m})-0.5$

$\mathrm{b}=$ constant, $-46.0 \mathrm{~s}$

RHR data at $75 \mathrm{~kW} / \mathrm{m}^{2}$ also show a good correlation but are not applied here since fewer materials were tested under this heat flux. The correlation coefficients at $75 \mathrm{~kW} / \mathrm{m}^{2}$ are, thus, more uncertain.

The results are also presented in Figure 5 as a simple stepwise ranking order according to small- and full-scale testing. A stepwise ranking order will of course overemphasize some small differences and conceal larger ones. However, the agreement is much better than a similar comparison for some of the current national fire test methods, using the same lining materials (20).

TABLE 4. Data for heat release during peak period and time to ignition used in the calculations for Figure 4.

\begin{tabular}{lcc}
\hline Material & $\begin{array}{c}\text { Heat release du- } \\
\text { ring peak period ime to ignition } \\
\text { at } 50 \mathrm{~kW} / \mathrm{m}^{2} \\
\mathrm{MJ} / \mathrm{m}^{2}\end{array}$ & $\begin{array}{c}\text { at 25 } \mathrm{kW} / \mathrm{m}^{2} \text { heat } \\
\text { flux }\end{array}$ \\
\hline Rigid polyurethane foam & 15.2 & $\mathrm{~s}$ \\
Textile wall-covering on rock-wool & 8.7 & 6 \\
Insulating fiber board & 18.7 & 31 \\
Expanded polystyrene & 30.8 & 39 \\
Medium density fiber board & 51.1 & 366 \\
Wood panel (spruce) & 25.3 & 115 \\
Paper wall-covering on particle board & 48.7 & 114 \\
Particle board & 42.8 & 132 \\
Melamine-faced particle board & 30.1 & 234 \\
Plastic wall-covering on gypsum board & 5.3 & 39 \\
Textile wall-covering on gypsum board & 11.3 & 108 \\
Paper wall-covering on gypsum board & 7.3 & 105 \\
Gypsum board & 5.5 & No ignition \\
\hline
\end{tabular}


[1] Particle board

* Insulating fiber board

a Medium density fiber board

- hood panel ispruce)

- Paper wall-covering on particle board $\times$ Melamine-faced particle board

+ Textile wall-covering on rock-wool

$\triangle$ Rigid polyurethane foom

* Expanded polystyrene
- Gypsura board

- Paper wall-covering on g.b.

- Plastic wall-covering on g.t.

- Textile wall-covering on g.b.

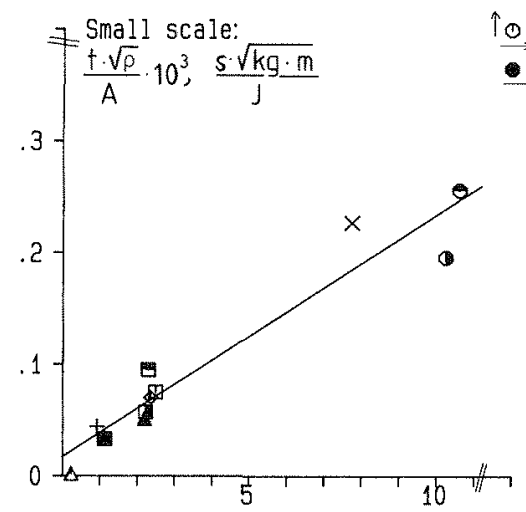

Full scale: Time to flashover, min.

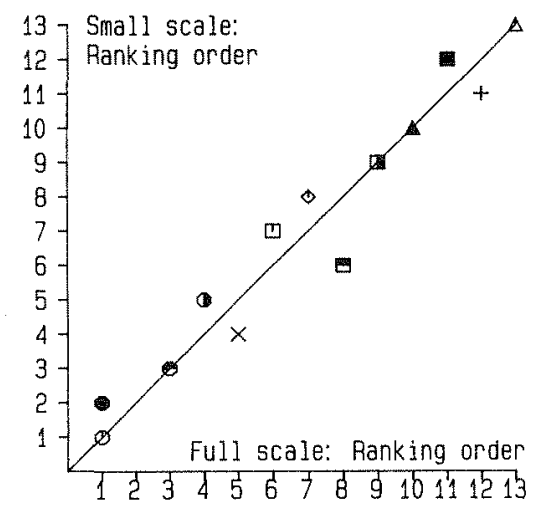

FIGURE 5 .

Stepwise ranking order of materials according to small-scale and fullscale fire testing at the same conditions as in Figure 4.

\section{FIGURE 4.}

The best correlation between a small-scale RHR-parameter and full-scale time to flashover with correlation coefficient 0.963 . The standard deviation for the calculated data is $0.023 \cdot 10^{-3}$.

\section{CONCLUSIONS}

A very simple empirical relation for surface Iinings has been found for predicting the time to flashover in a full-scale room fire test based on bench-scale measurements of heat release, the time to iqnition, and the density of the lining. It is thus expressed in terms of basic, physical parameters but does not assume a specific physical description or a theoretical model of the fire.

Among different heat release parameters, the total heat release during peak period gave the best correlation. It can also be determined more accurately than $e \cdot g$. the peak height. Heat release at $50 \mathrm{~kW} / \mathrm{m}^{2}$ and time to ignition at $25 \mathrm{~kW} / \mathrm{m}^{2}$ seems to be preferable, but other heat fluxes might equally well be useo when analyzing further data. The addition of density as a parameter was important and reflects the influence of thermal inertia on the growth of room fires. However, the addition of the full thermal inertia did not improve the correlation further, probably since no new independent parameters are added. 
The relation was shown to be valid for the 11 different lining materials which caused flashover in the room fire test. The two materials which did not cause flashover can not be directly correlated, but their smal1-scale data at least indicate longer times to flashover than for the other lining materials. However, the application may not be generalizable to other, untested materials. It also should not be applied to other fuil-scale geometries until further investigated, but may of course be modified if desirable. Other parameters, e.g. the thickness of the linings, might also be needed in the fully general case.

The main advantage is to provide a simple link between small-scale and full-scale fire behaviour for surface linings. Such links will be necessary for providing useful tools to predict full-scale fire behaviour. They may also form a basis for classification systems making the new fire test methods practically useful in building codes.

\section{REFERENCES}

1. ASTM E-5 Proposal P 190: Proposed test method for Heat and visible smoke release rates for materials and products using an oxygen consumption calorimeter. Annual Book of ASTM Standards vol. 04.07, pp. $1203-1219,1986$.

2. ASTM E-5 Proposal: Proposed method for Room fire test of wall and ceiling materials and assemblies. Annual Book of ASTM Standards Part 18, pp. 1618-1638, 1982.

3. Babrauskas, V.: Development of the cone calorimeter. A bench scale heat release rate apparatus based on oxygen consumption. Fire and Materials, vol. 8, no. 2, pp. 81-95, 1984.

4. Babrauskas, V.: Bench-scale methods for predictions of full-scale fire behaviour of furnishings and wall linings. Technology Report 84-10, Society of fire protection engineers, Boston, 1984.

5. Babrauskas, V.: Comparative rates of heat release from five different types of test apparatures. J. Fire Sciences, vol. 4, March/April, pp. 148-159, 1986 .

6. Bullen, M.L.: A comparison of flashover times in small-scale fires using test data. Fire and Materials, vol. 1, no. 2, pp. 74-75, 1976.

7. ISO DP 9705: Room fire test in full scale for surface products. IS0/TC 92/SC 1/WG7 - DoC N 40, 1986.

8. ISO TR 3814: Tests for measuring reaction-to-fire of building materials. Their development and application. ISO Final Draft Technical Report 3814, 1986.

9. IS0/DIS 5657: Fire tests - Reaction to fire - Ignitability of building products.Draft International Standard, ISO/DIS 5657, 1985.

10. Magnusson, S.E. and Sundström, B.: Modeling room fice growth - Combustible lining materials. ASTM Special Technical Publication 882, 1985. 
11. Nordtest NT Fire 025: Surface products: Room fire test in full scale. Nordtest, Helsinki, 1986.

12. Nussbaum R.M. and Ustman, B.A-L.: Larger specimens for determining rate of heat release in the cone calorimeter. Fire and Materials, vol. 10 , no. 3/4, pp. 151-160, 1986.

13. Smith, E.E. and Satija, 5.: Release rate model for developing fires. J. Heat Transfer, vol. 105, May, pp. 281-287, 1983.

14. Smith, E.E.: Mathematical model of a fire in a compartment having combustible walls and ceiling. AIChE Symp. Series, vol. 81, no. 246, pp. 64-74, 1985.

15. Sundström, B.: Full scale fire testing of surface materials. Measurement of heat release and productions of smoke and gas species. Technical Report 1986: 43, Swedish National Testing Institute, 1986.

16. Thomas, P.H. and Bullen, M.L.: On the role of kpc of room lining materials in the growth of room fires. Fire and Materials, vol. 3, no. 2, pp. 68-73, 1979 .

17. Thomas, P.H.: Testing products and materials for their contribution to flashover in rooms. Fire and Materials, vol. 5, no. 3, pp. 103-111, 1981.

18. Wickström, U. and Göransson, U.: Prediction of heat release rates of large scale room fire tests based on cone calorimeter results. ASTM Journal of Testing and Evaluation, vol. 15, no. 6, pp. 364-370, 1987.

19. Ustman, B.A-L., Svensson, I.G. and Blomqvist, J.: Comparison of three test methods for measuring rate of heat release. Fire and Materials, vol. 9, no. 4, pp. 76-184, 1985.

20. Ustman, B. and Nussbaum, R.: National standard fire tests in small scale compared with the full scale IS0 room test. Report I 8702017, Swedish Institute for Wood Technology Research, 1987. 